\title{
Redes sociales académicas vs. repositorios institucionales. ¿Por qué no las dos? Una reflexión desde la experiencia de trabajo en el repositorio Dadun, de la Universidad de Navarra
}

María Amparo Cózar Santiago | Servicio de Bibliotecas, Universidad de Navarra

URL de la contribución <www.iaph.es/revistaph/index.php/revistaph/article/view/4653>

En el año 2008 nacía Dadun, el repositorio institucional de la Universidad de Navarra. Según El paisaje de los repositorios institucionales open Access en España, en mayo del 2007 había registrados 27 repositorios de instituciones españolas en ROAR (Registry of Open Access Repositories).

Mucho se habló al principio de la vida de los repositorios sobre el archivo delegado y el autoarchivo. A los bibliotecarios, esta última opción es la que nos parecía más adecuada, es decir, que el investigador gestionara su propia investigación. Que fuera él mismo el que, rellenando unos sencillos pasos, alimentara el repositorio de su institución con las publicaciones que iba generando en su currículum.

Sin embargo con el paso del tiempo se vio que cada investigador, y sobre todo cada campo científico, se comportaba de manera distinta, y que el archivo delegado se imponía frente al autoarchivo.

No ocurría lo mismo con las redes sociales académicas que empezaron a aparecer como una nueva herramienta de difusión de la investigación. A diferencia de los repositorios, estas funcionaban perfectamente con un autoarchivo por parte del investigador, y casi podría decirse que de manera inmediata a la publicación del paper.

Herramientas como Academia.edu o ResearchGate comenzaron a tener el éxito que esperábamos para nuestros repositorios, y empezaron a alojar la producción de nuestros investigadores, quedando los repositorios en un segundo o incluso a veces, un tercer lugar de depósito de las publicaciones científicas.

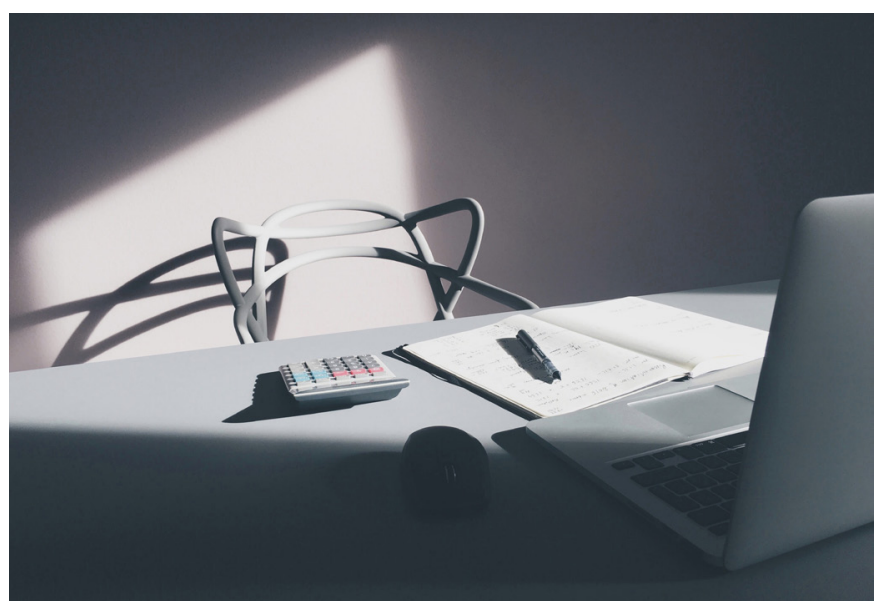

Cada investigador, y sobre todo cada campo científico, se comporta de manera distinta, y el archivo delegado se impone frente al autoarchivo

¿Por qué ellas tuvieron ese éxito que no conseguían nuestros repositorios? A las razones que señala Javier Gómez-Castaño (ver en esta misma sección, pp. 73-75), añadiría alguna más:

> Fácil, rápida y sencilla interacción con el autor.

$>$ Alertas al investigador de nuevas publicaciones suyas.

$>$ Popularidad.

$>$ Facilidad de uso.

> Conexión entre investigadores de distintas instituciones.

Cualquier investigador ve de una manera clara las ventajas y la necesidad de estar presente en las redes sociales, no así en los repositorios, en los que el bibliotecario ha de estar continuamente haciendo marketing de las ventajas de depositar la producción en el repositorio, cuando no apoyarse en mandatos o recomendacio- 
a debate Repositorios y redes sociales académicas para la transferencia del conocimiento abierto

| coordina Remedios Melero Melero

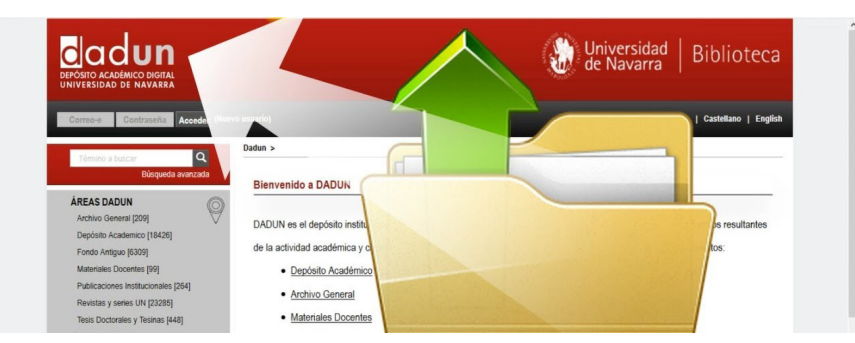

Dadun, Depósito Académico Digital de la Universida de Navarra

nes institucionales. Además de gestionar el repositorio, sus desarrollos, su actividad diaria, formación de usuarios, etc. se añade como tarea principal de los gestores de repositorios el marketing de la herramienta, así como la formación en el depósito y archivo de la publicación.

En un afán por parecernos y ganar la batalla a las redes sociales, los repositorios empezaron a trabajar en desarrollos que ofrecieran un valor añadido al autor. Hay que señalar aquí que el software en el que se apoya la mayoría de los repositorios españoles (DSpace) ha ido avanzando en la incorporación de desarrollos. Sin embargo, muchas veces se trata de desarrollos propios de la institución para mejorar y enriquecer la herramienta.

Otra desventaja que hemos de tener en cuenta es que son muchos los repositorios que, ante la falta de personal informático en nuestras plantillas, nos vemos ante la necesidad de contratar empresas externas que gestionen el mantenimiento, actualización y desarrollos de nuestros repositorios.

Se han hecho avances tecnológicos intentando asemejarnos a las redes sociales académicas. Puede recordarse el presentado por Roderic, el repositorio de la Universidad de Valencia, en el workshop de Córdoba del 2015, sobre Desarrollo de perfiles de autores en DSpace para el repositorio institucional.

Mucho más extendida -y en el que muchos repositorios ya han avanzado o se encuentran actualmente en ello- es la conexión de las distintas plataformas de una institución: conexión entre OJS y el software del repositorio, o entre el CRIS (Current Research Information
System) y el repositorio. Su objetivo principal es facilitar al investigador la gestión de su producción y no tener que trabajar en varias plataformas. Con una sola gestión debería estar presente su investigación en todas las plataformas de la institución. Es fácil encontrar alguna presentación al respecto, sirva de apoyo la presentada por la Universidad de Navarra en el CRECS de Logroño de 2019. Estos avances tecnológicos lo que buscan, en definitiva, es facilitar la tarea de archivo de la producción en las herramientas de la universidad, de tal modo que el investigador no acuda a otras redes externas de la institución.

Desde Dadun nos preguntamos por qué no alinearnos con las redes sociales académicas en lugar de intentar ganar la batalla. De este modo se comenzó a transmitir la idea entre los investigadores de por qué no estar presente en las dos, pero buscando de cada una el beneficio que aporta.

Invitamos a nuestros investigadores a estar presente en las redes sociales, porque veíamos claramente las ventajas que ello les ofrecía. Sin embargo, les pedíamos que el pdf siempre estuviera alojado en el repositorio, y que sus diferentes perfiles en redes apuntasen, a través del enlace permanente del registro del repositorio (handle) a la herramienta de la institución.

De este modo los investigadores no dejan de estar en las redes sociales académicas, que es lo que a ellos les interesa, y además logran otra serie de ventajas:

> Cumplir con las políticas editoriales: a diferencia de las redes sociales, en el repositorio se revisan las políticas editoriales de los documentos que se suben por parte del personal bibliotecario.

> Revisión y comprobación de los metadatos.

$>$ Visibilidad de la institución.

$>$ Un único punto de recogida de las estadísticas.

$>$ Coste gratuito.

$>$ Etc. 


\section{BIBLIOGRAFÍA}

- MELERO, R. (2008) El paisaje de los repositorios institucionales open access en España. BiD: textos universitaris de biblioteconomia i documentació [en línea], n. ${ }^{\circ} 20$ (juny), 2008 <http://bid.ub.edu/20meler4.htm> [Consulta: 24/04/2020]

- GÓMEZ-CASTAÑO, J. (2020) Repositorios digitales y redes sociales académicas: ¿una coexistencia necesaria? revista $\mathrm{PH}$ [en línea], n. ${ }^{\circ} 100,2020$, pp. XX-XX <www.iaph.es/revistaph/ index.php/revistaph/article/view/4628> [Consulta: 24/04/2020]

- BARRUECO CRUZ, J. M; NAVALÓN, J. A. (2015) Desarrollo de perfiles de autores en DSpace para el repositorio institucional de la Universitat de València [comunicación]. En XIV Workshop Rebiun de Poyectos Digitales / VI Jornadas OSRepositorios (Córdoba, 11-13 de marzo de 2015) <http://hdl. handle.net/10396/12622> [Consulta: 24/04/2020]

- HEREDERO, R; AZNAR, D.; CÓZAR, A.; ALONSO, M. (2019) Conectando nuestras aplicaciones: CRIS, DSPACE y OJS. En $9^{a}$ Conferencia internacional sobre revistas de Ciencias Sociales y Humanidades (Logroño, 23 y 24 de mayo del 2019) <https://www.slideshare.net/presentacionesEPI/conectandonuestras-aplicaciones-cris-dspace-y-ojs-rafael-herederouniversidad-de-navarra-en-colaboracin-con-david-aznaramparo-czar-y-mercedes-alonso> [Consulta: 24/04/2020] 